\title{
Effects of Wheat Germ Extract on the Severity and Systemic Symptoms of Primary Dysmenorrhea: A Randomized Controlled Clinical Trial
}

\author{
Maryam Atallahi $^{1,2}$; Sedigheh Amir Ali Akbari ${ }^{3, *}$; Faraz Mojab $^{4}$; Hamid Alavi Majd ${ }^{5}$ \\ ${ }_{1}^{1}$ Department of Midwifery, Shahid Beheshti University of Medical Sciences, International Branch, Tehran, IR Iran \\ ${ }^{2}$ Faculty of Nursing and Midwifery, Hamadan University of Medical Sciences, Hamadan, IR Iran \\ 3 Department of Midwifery, Faculty of Nursing and Midwifery, Shahid Beheshti University of Medical Sciences, Tehran, IR Iran \\ Department of Midwifery, Faculty of Nursing and Midwifery, Shahid Beheshti University of Medical
${ }^{4}$ Department of Pharmacognosy, Shahid Beheshti University of Medical Sciences, Tehran, IR Iran \\ ${ }^{5}$ Department of Pharmacognosy, Shahid Beheshti University of Medical Sciences, Tehran, IR Iran \\ ${ }^{*}$ Corresponding Author: Sedigheh Amir Ali Akbari, Department of Midwifery, Faculty of Nursing and Midwifery, Shahid Beheshti University of Medical Sciences, Vali-asr and Niayesh \\ Junction, Tehran, IR Iran. Tel: +98-9123142669, Fax:+98-2188202512, E-mail: asa_akbari@yahoo.com
}

Received: April 17, 2014; Revised: June 1, 2014; Accepted: July 3, 2014

\begin{abstract}
Background: Primary dysmenorrhea is one of the most common disorders in women and the main cause of absenteeism from work and school.

Objectives: Considering the anti-inflammatory properties of wheat germ, the present study examined the effects of wheat germ extract on the severity and systemic symptoms of primary dysmenorrhea.

Patients and Methods: This triple-blinded clinical trial was performed on 80 employed women in hospitals affiliated with Hamadan University of Medical Sciences (Hamadan, IR Iran). Subjects were allocated to two groups of 45 patients. Three 400-mg capsules of wheat germ extract or placebo were used daily, between the 16th day of the menstrual cycle to the fifth day of the next menstrual cycle for two consecutive months. Pain intensity was measured by a visual analogue scale thrice a day and a four-point verbal rating scale was employed to assess systemic symptoms.

Results: Pain severity decreased only in the wheat germ extract group $(\mathrm{P}<0.001)$ and there was no statistically significant change in the placebo group. In the wheat germ extract group, the pain severity decreased from 4.701 at baseline to 1.120 at the second cycle. The reduction in total scores of systemic symptoms of dysmenorrhea was statistically significant only in the wheat germ extract group $(\mathrm{P}<$ 0.001 ) and there was not a statistically significant change in the placebo group. It revealed statistically significant differences in systemic symptoms associated with dysmenorrhea including fatigue, headache, and mood swings in experimental group.

Conclusions: Wheat germ extract seems to be an effective treatment for dysmenorrhea and its systemic symptoms, probably because of its anti-inflammatory effects.
\end{abstract}

Keywords:Dysmenorrhea; Herbal Medicines; Wheat Germ

\section{Background}

Dysmenorrhea or painful menses is a common gynecological condition (1-3). It is commonly categorized into two types of primary and secondary dysmenorrhea based on pathophysiology. Primary dysmenorrhea is painful menses without organic diseases that refers to monthly suprapubic pain beginning between several hours before and a few hours after the onset of menstrual bleeding, and secondary dysmenorrhea is painful menses in association with an identifiable disease (4-6). Primary dysmenorrhea is associated with some symptoms such as nausea, vomiting, diarrhea, headache, fatigue, dizziness, and syncope $(7,8)$. Pain intensity in dysmenorrhea can be mild (pain that does not disturb daily activities and does not require painkillers), moderate (pain that slightly interferes with daily routines but can be managed with painkillers), and severe (pain that completely prevents daily life activities) (9).

According to previous studies, 70\% to $91 \%$ of young girls have dysmenorrhea (10) and about $14 \%$ to $23 \%$ experience severe symptoms. Dysmenorrhea is the leading cause of absenteeism from the work or school and reduced quality of life (7, 10-13).

The most important cause of primary dysmenorrhea is increased production of prostaglandins (14-17). Various methods including local heat therapy, herbal therapy, reflexology, acupuncture, and the administration of thiamine, vitamin E, magnesium supplementation, acetaminophen, aspirin, and oral contraceptives have been suggested to control and treat dysmenorrhea (3, 18-25). Herbal therapy is a type of traditional medicine (2) that uses herbal medicines as more reliable, more effective, and more economical alternatives for chemical medications (26). Naturally occurring agents used to treat dysmenorrhea include Rosa damascena $(27,28)$, fenugreek seed (2), fennel $(29,30)$, Shirazi Thymus (4), and valerian (31). Among herbal medicines, wheat germ is rich in vitamins and minerals. The positive effect of wheat germ consumption has been reported in treatment of diseases 
such as cancers, obesity, diabetes, asthma, anemia, eczema, high blood pressure, ulcers, and gastritis. Wheat germ is comprised of magnesium, zinc, calcium, vitamin E, vitamin $C$, vitamin $B_{12}$, vitamin $B_{6}$, thiamin, riboflavin, niacin, folic acid, and iron (32-34). Various studies have been conducted to assess the positive effects of some wheat germ compounds (vitamins $\mathrm{E}_{1} \mathrm{~B}_{6}$, and $\mathrm{B}_{1}$ ) on reducing symptoms of dysmenorrhea.

Proctor and Farquhar reported the efficiency of vitamin $\mathrm{B}_{6}$ in relieving the symptoms of dysmenorrhea (21). In addition, vitamin $\mathrm{E}$ intake reduces the intensity of dysmenorrhea $(35,36)$. In other studies, positive effects of vitamin $B_{1}$ in dysmenorrhea have been addressed (37). Wheat germ has anti-inflammatory, sedative, antidepressant, and soothing properties and is rich in vitamins $\mathrm{E}, \mathrm{B}_{12}, \mathrm{~B}_{6}$, magnesium, zinc, and calcium.

\section{Objectives}

Considering the properties of wheat germ, this study was conducted to determine the effects of wheat germ extract on the severity and systemic manifestations of primary dysmenorrhea.

\section{Patients and Methods}

This triple-blinded randomized clinical trial was performed on 90 women working in governmental hospitals affiliated with Hamadan University of Medical Sciences (Hamadan, IR Iran) from September 2013 to March 2014.

The study protocol was approved by the Ethics Committee of Shahid Beheshti University of Medical Sciences. After getting permission from the Ethics Committee (Ethical code 116/2879; date 30/9/2013), and registering the study in the Iranian Registry of clinical trial (IRCT ID: 201310286807N8), participants were informed about the purpose and methods of the study and the interested women were invited to participate in this study. Among 624 employed women in hospitals, 312 reported primary dysmenorrhea. After more assessments, 90 individuals were enrolled in the study.

The inclusion criteria were as follows: patients with 20 to 45 years of age, body mass index (BMI) of 19.8 to $26 \mathrm{~kg} / \mathrm{m}^{2}$, having no night shifts, no smoking, regular menstrual periods with 21-day to 35-day cycles and threeday to ten-day bleeding period, no identified physical or psychological diseases, no relatives death and divorce in the preceding three months, and no antidepressants, hormones, or contraceptives use in the preceding three months. The exclusion criteria were relatives' death and divorce, adverse events, and pregnancy.

The two groups were matched for variables related to dysmenorrhea and systemic symptoms including age, weight, age at menarche, and BMI.

Sample size was estimated using the following formula: $\left.\mathrm{N}=\left(\mathrm{Z}_{\alpha / 2}+\mathrm{Z}_{\beta}\right)^{2} \sigma^{2}\right) / \varepsilon^{2}$

With $95 \%$ confidence interval, a minimum sample size of 90 participants was determined.
A self-reported checklist was used to collect data on the intensity of primary dysmenorrhea, the systemic symptoms associated with dysmenorrhea, and the number of sedative drugs taken for dysmenorrhea. Its validity was confirmed through content validity, and test-retest method was used to assess its reliability $(r=0.91)$. First, maximum pain intensity during two consecutive menstrual cycles were recorded in forms number 2 and 3.

During the first three days of menstruation, pain intensity was measured by a visual analogue scale (VAS; a 10$\mathrm{cm}$ tape) three times a day. Scores of one through three, four through seven, and eight through ten on the VAS indicated mild, moderate, and severe pain, respectively. A four-point verbal rating scale from zero to three was employed to assess the intensity of the associated systemic symptoms (fatigue, diarrhea, syncope, nausea and vomiting, lack of energy, headache, and mood swings); the validity and reliability of this scale was confirmed in various studies (37-41). After obtaining written informed consent, the table of random numbers was used to allocate the participants to any of the groups receiving wheat germ extract or placebo.

First, the extraction was performed using ethanol 70\% and repeated three times and each time for 24 hours. The dried extracts were used to produce capsules containing $400 \mathrm{mg}$ of wheat germ extract. Three capsules of wheat germ extract or placebo were administered daily, from the 16th day through the fifth day of the next menstrual cycle for two consecutive months. The subjects received the medicine and filled out forms number 2 and 3 again.

The subjects could use NSAIDs if required; however, they were asked to take these medications equal or longer than one hour after taking the study capsule. Patients were instructed to score and register the pain severity before consumption of the sedative. The questionnaires were collected after two months of intervention and the mean intensity of primary dysmenorrhea and its associated systemic symptoms were determined. Among 90 participants, one person was excluded due to pregnancy, three due to digestive complications, and six due to missing or inappropriately taking the medicines. The final analysis included 80 women: 42 had received wheat germ extract and 38 had received placebo (Figure 1 ).

Data were analyzed with SPSS v.17 (SPSS Inc., Chicago, IL, USA) using t test, GEE logistic regression, Friedman test, McNemar test with Bonferroni, and Mann-Whitney U test. The independent-samples t-test was used to compare age, weight, BMI, age at menarche, and duration of menstrual cycle between study groups. The Friedman test was employed to compare pain severity and the systemic symptoms associated with menstruation between the three periods within groups, and the Mann-Whitney U test was used to compare the findings between the study groups. If the results of the Friedman test were significant, the periods were compared in pairs via McNemar test with Bonferroni correction. P value $<0.05$ was considered as statistically significant. 


\section{Results}

The length of the menstrual period in all participants ranged from three to ten days and the interval between the periods ranged from 21 to 35 days. No one in the groups exercised professionally and regularly. In order to control the confounding factors, both groups were matched for age, weight, BMI, age at menarche, length of menstrual cycle, menstruation duration, and marital status and there was not a statistically significant difference between the two groups with regard to these variables (Table 1 ).

As Tables 2 and 3 show, the study groups were matched for the severity of the pain and systemic manifestations, and there was no statistically significant difference between them in this respect before the intervention.

The reduction in severity of pain was statistically significant only in the wheat germ extract group $(\mathrm{P}<0.001)$ and there was no statistically significant change in the placebo group (Table 2). The severity of the systemic symptoms associated with dysmenorrhea had reduced in both groups; however, this reduction was significantly greater in the wheat germ extract group in comparison to placebo group $(\mathrm{P}<0.001)$ (Tables 3 and 4$)$. The results of mixed model analysis or GEE analysis are shown in Table 5. The effect of treatment group on the severity and systemic manifestations of dysmenorrhea was significant $(\mathrm{P}<0.05)$.

Neither of the groups showed changes in the duration and extent of bleeding and there was no statistically significant difference between the groups in this regard. The number of consumed painkillers remarkably reduced after intervention in the wheat germ extract group $(\mathrm{P}<$ 0.001) while there was no statistically significant changes in the placebo group with regard to this score. In addition, $95.2 \%$ of the wheat germ extract group and $92.9 \%$ of the placebo group participants did not report any complications.

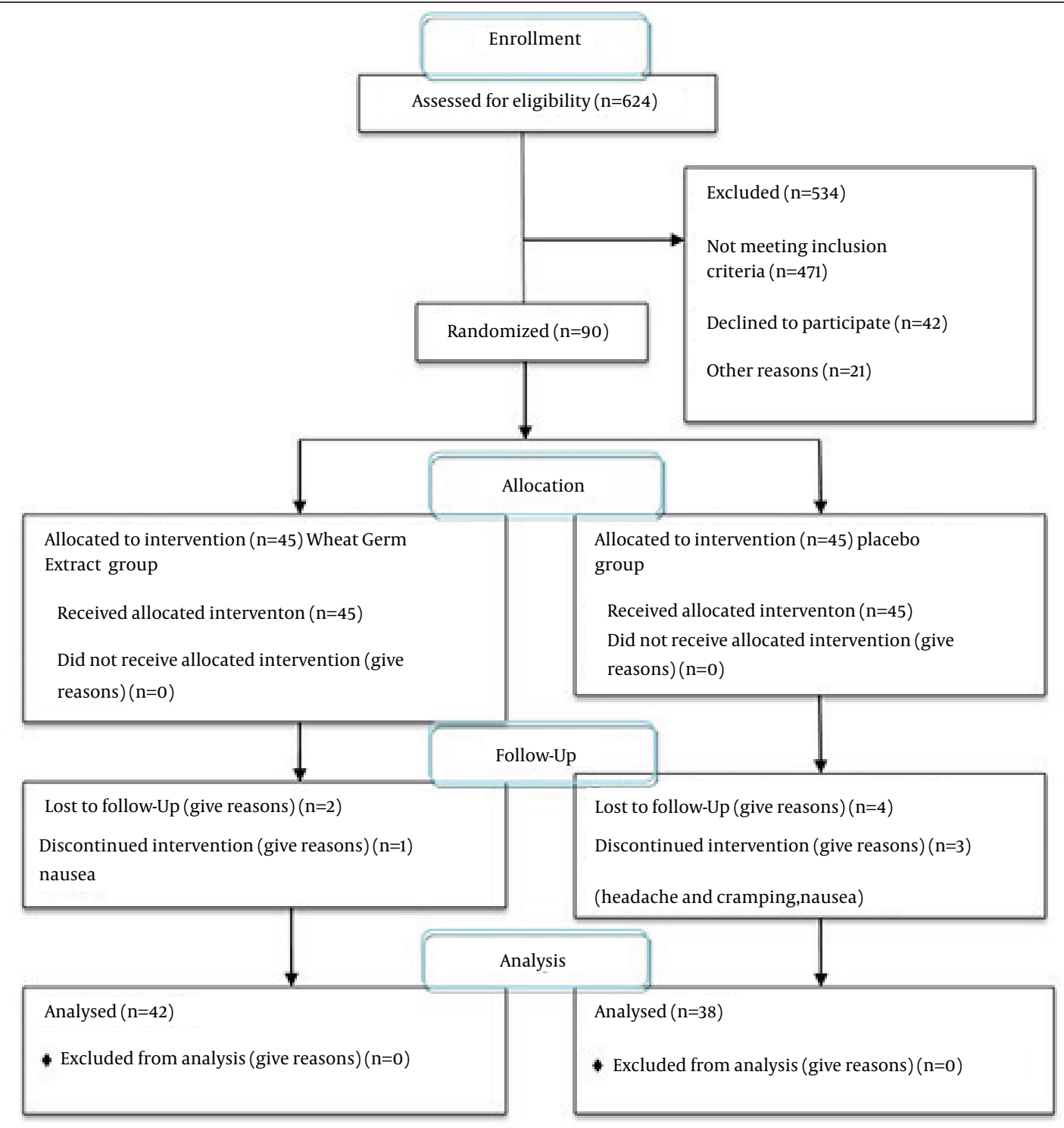

Figure 1. Flow of Participants Through the Research. 
Atallahi M et al.

Table 1. Demographic Characteristics of the Study Groups a

\begin{tabular}{lccc}
\hline & \multicolumn{2}{c}{ Treatment Categories } & P Value \\
\hline Variable & Wheat Germ Extract & Placebo & 0.637 \\
\hline Age, $\mathbf{y}$ & $33.452 \pm 5.89$ & $32.842 \pm 5.58$ & 0.781 \\
\hline Weight, $\mathbf{~ k g}$ & $59.166 \pm 9.52$ & $58.592 \pm 8.78$ & 0.328 \\
BMI $^{\text {b }} \mathbf{~ k g / \mathbf { m } ^ { 2 }}$ & $23.439 \pm 1.86$ & $23.026 \pm 1.88$ & 0.348 \\
\hline Length of Menstrual Cycle, $\mathbf{d}$ & $27 \pm 2.81$ & $28.026 \pm 2.07$ & 0.289 \\
Age at Menarche, $\mathbf{y}$ & $13.571 \pm 1.48$ & $13.921 \pm 1.44$ & 0.625 \\
Marital Status & & & 23.7 \\
\hline Single & 28.6 & 76.3 & \\
\hline Married & 71.4 & &
\end{tabular}

\footnotetext{
a Data are presented as mean \pm SD or percent.

$\mathrm{b}$ Body mass index.
}

Table 2. Severity of Dysmenorrhea Before and After the Intervention in Study Groups a, b

\begin{tabular}{lcccc}
\hline Treatment Round & Before Treatment & Four Weeks After Treatment & Eight Weeks After Treatment & P Value \\
\cline { 2 - 5 } & Percentiles 50,(25-75) & Percentiles 50,(25-75) & Percentiles 50, (25-75) & \\
\hline Wheat Germ Extract & $4.791(1.916-6.666)$ & $2.121(0.833-3.333)$ & $0.606(0-1.553)$ & 0.000 \\
Placebo & $4.999(1.666-6.874)$ & $3.333(0.75-6.666)$ & $3.610(0.0-0.666)$ & 0.203 \\
Pvalue & 0.509 & 0.04 & 0.003 & \\
\hline
\end{tabular}

a Man-Whitney U test.

b Friedman and Bonferroni.

\begin{tabular}{lcccc}
\hline Table 3. Severity of Systemic Signs Associated With Dysmenorrhea Before and After the Intervention in Study Groups a,b \\
\hline Treatment Round & Before Treatment & Four Weeks After Treatment & Eight Weeks After Treatment & P Value \\
\cline { 2 - 5 } & Percentiles, 50 (25-75) & Percentiles, 50 (25-75) & Percentiles, 50 (25-75) & $0.227(0.116-0.295)$ \\
\hline Wheat Germ Extract & $0.690(0.518-1.020)$ & $0.272(0.168-0.428)$ & 0.000 \\
Placebo & $0.699(0.428-0.959)$ & $0.541(0.285-0.832)$ & $0.525(0.285-0.862)$ & 0.20 \\
Pvalue & 0.620 & 0.001 & 0.000 & \\
\hline
\end{tabular}

${ }^{\mathrm{a}}$ Man-Whitney U test.

b Friedman \& Bonferroni.

Table 4. Severity of Systemic Signs Associated With Dysmenorrhea, as Measured on a Multidimensional Verbal Scale (Score Range $0-3)^{\mathrm{a}}$

\begin{tabular}{|c|c|c|c|c|c|c|c|c|c|}
\hline \multirow{3}{*}{$\begin{array}{l}\text { Systemic } \\
\text { Sign }\end{array}$} & \multicolumn{3}{|c|}{ Baseline } & \multicolumn{3}{|c|}{ First Cycle } & \multicolumn{3}{|c|}{ Second Cycle } \\
\hline & \multicolumn{3}{|c|}{ Percentiles, 50 (25-75) } & \multicolumn{3}{|c|}{ Percentiles, 50 (25-75) } & \multicolumn{3}{|c|}{ Percentiles, 50 (25-75) } \\
\hline & Wheat Germ & Placebo & PValue & Wheat Germ & Placebo & P Value & Wheat Germ & Placebo & P Value \\
\hline Fatigue & $1.35(0.999-1.912)$ & $1.292(0.999-1.999)$ & 0.343 & $0.363(0.0-0.999)$ & 0.999 (0.0-1.999) & 0.020 & $0.000(0.0-0.818)$ & $0.999(0.0-1.795)$ & 0.001 \\
\hline $\begin{array}{l}\text { Nausea, } \\
\text { Vomiting }\end{array}$ & $0.000(0.0-0.625)$ & $0.000(0.0-1)$ & 0.888 & $0.000(0.0-0.082)$ & $0.000(0.0-1)$ & 0.315 & $0.000(0.0-0.0)$ & $0.000(0.0-0.330)$ & 0.125 \\
\hline $\begin{array}{l}\text { Lack Of } \\
\text { Energy }\end{array}$ & $0.000(0.0-1)$ & $0.000(0.0-1)$ & 0.979 & $0.000(0.00-0.00)$ & $0.000(0.0-1)$ & 0.273 & $0.000(0.00-0.00)$ & $0.000(0.0-0.625)$ & 0.368 \\
\hline Headache & $0.0000(0.0-1.999)$ & 1.164 (0.0-1.999) & 0.459 & $0.181(0.0-0.999)$ & $1.272(0.0-1.999)$ & 0.006 & $0.000(0.0-0.545)$ & $1.136(0.0-1.999)$ & 0.000 \\
\hline Diarrhea & $0.625(0.0-1.342)$ & $0.000(0.0-1.041)$ & 0.276 & $0.000(0.0-0.999)$ & $0.000(0.0-0.999)$ & 0.832 & $0.000(0.0-0.0)$ & $0.000(0.0-0.999)$ & 0.321 \\
\hline $\begin{array}{l}\text { Mood } \\
\text { Swings }\end{array}$ & $0.999(0.0-1.669)$ & $0.999(0.0-1.961)$ & 0.767 & $0.545(0.0-0.8636)$ & $0.999(0.0-0.999)$ & 0.999 & $0.000(0.0-0.272)$ & $0.999(0.0-1.525)$ & 0.001 \\
\hline Syncope & $0.000(0.0-0.0)$ & $0.000(0.0-0.0)$ & 0.223 & $0.000(0.0-0.0)$ & $0.000(0.0-0.0)$ & 0.569 & $0.000(0.0-0.0)$ & $0.000(0.0-0.0)$ & 0.291 \\
\hline
\end{tabular}

a Man-Whitney U test. 
Table 5. GEE Model of Dysmenorrhea, Fatigue, Diarrhea, Syncope, Nausea and Vomiting, Lack of Energy, Headache, and Mood Swings

\begin{tabular}{|c|c|c|c|}
\hline & Estimate & Standard Error & P Value \\
\hline \multicolumn{4}{|l|}{ Dysmenorrhea } \\
\hline Wheat Germ Extract & $\mathrm{B}=1.578$ & 0.510 & 0.002 \\
\hline Placebo & & Reference group & \\
\hline \multicolumn{4}{|l|}{ Fatigue } \\
\hline Wheat Germ Extract & $\mathrm{B}=0.328$ & 0.1372 & 0.017 \\
\hline Placebo & & Reference group & \\
\hline \multicolumn{4}{|l|}{ Nausea, Vomiting } \\
\hline Wheat Germ Extract & $\mathrm{B}=0.129$ & 0.1091 & 0.238 \\
\hline Placebo & & Reference group & \\
\hline \multicolumn{4}{|l|}{ Lack of Energy } \\
\hline Wheat Germ Extract & $\mathrm{B}=0.107$ & 0.136 & 0.434 \\
\hline Placebo & & Reference group & \\
\hline \multicolumn{4}{|l|}{ Headache } \\
\hline Wheat Germ Extract & $B=0.559$ & 0.168 & 0.001 \\
\hline Placebo & & Reference group & \\
\hline \multicolumn{4}{|l|}{ Diarrhea } \\
\hline Wheat Germ Extract & $B=0.055$ & 0.1374 & 0.686 \\
\hline Placebo & & Reference group & \\
\hline \multicolumn{4}{|l|}{ Mood Swings } \\
\hline Wheat Germ Extract & $\mathrm{B}=0.276$ & 0.1327 & 0.031 \\
\hline Placebo & & Reference group & \\
\hline \multicolumn{4}{|l|}{ Syncope } \\
\hline Wheat Germ Extract & $\mathrm{B}=0.061$ & 0.0545 & 0.260 \\
\hline Placebo & & Reference group & \\
\hline
\end{tabular}

\section{Discussion}

The present study was the first to investigate the use of wheat germ extract in the treatment of dysmenorrhea. The results showed that wheat germ extract reduced the severity of pain $(\mathrm{P}<0.001)$. While there was no statistically significant difference in the placebo group. There was a significant difference in pain intensity between groups $(\mathrm{P}<0.001)$. The severity of the systemic symptoms associated with dysmenorrhea was reduced in both groups, but this reduction was significantly greater in the wheat germ extract group in comparison with placebo group $(\mathrm{P}<0.001)$. The Man-Whitney U test revealed statistically significant differences between both groups in systemic symptoms associated with dysmenorrhea including fatigue, headache, and mood swings.

Wheat germ activates neuropeptides, cytokines, and macrophages due to its anti-inflammatory properties and hence, can decrease inflammation within two weeks. Moreover, daily use of 20 to $100 \mathrm{~mL}$ of wheat germ extract has been suggested to alleviate the symptoms of ulcerative colitis (e.g. abdominal pain) by $78 \%$ (32). Such find- ings can be justified by anti-inflammatory properties of wheat which can in turn enhance blood circulation, remove blood stasis, and reduce pain (42).

Previous researches have not directly addressed the effect of wheat germ extract on dysmenorrhea. In addition, the positive effects of some components of wheat germ such as vitamin $B_{12}$, thiamin, pyridoxine, magnesium, and vitamin $\mathrm{E}$ on the intensity of dysmenorrhea have been previously highlighted (21). Vitamin $B_{12}$ acts as an antioxidant and lowers the levels of prostaglandins and leukotrienes; thus, it can relieve pain. The benefits of omega-3 plus vitamin $\mathrm{B}_{12}$ in easing menstrual pains have been thoroughly described (38). Therefore, the desirable effects of wheat germ on our participants might be due to its vitamin $\mathrm{B}_{12}$ content.

Wheat germ is also rich in vitamin $\mathrm{E}$, an antioxidant that can mitigate the symptoms of dysmenorrhea by preventing arachidonic acid oxidation and the production of prostaglandins (36). Twice-daily supplementation with 200 units of vitamin E has been reported to reduce the duration and severity of primary dysmenorrhea (43). Therefore, the desirable effects of wheat germ on our participants might be due to its vitamin E content.

A study suggested daily intake of vitamin D (300000 $\mathrm{IU} / \mathrm{mL}$ ) from five days before the menstrual period to lower the pain of dysmenorrhea (44). Therefore, the desirable effects of wheat germ on our participants might be caused by vitamin D content of wheat germ. Wheat germ also contains vitamin $B_{1}$. Receiving 100-mg vitamin B1 daily for three successive cycles has been proved to alleviate the pain as effectively as 400-mg ibuprofen without having any particular side effects (45). Magnesium is another component of wheat germ that its daily intake ( $4.5 \mathrm{mg}$ three times a day) from seven days before through the third day after the initiation of menstrual period has been confirmed to mitigate the severity of dysmenorrhea (46). Wheat germ also contains high amounts of calcium which is beneficial for reducing cramping and pain (47).

We found wheat germ consumption soothing to headaches (a systemic symptom associated with dysmenorrhea). It seems sensible as wheat germ has high levels of magnesium and vitamin $\mathrm{B}_{6}$ whose effects in treating migraines and generally headaches have been proven (48). Daily use of magnesium has also been reported to have positive effects on relieving headaches (49). The use of wheat reduces pains including headache (42). Furthermore, the daily use of wheat germ has been effective in improving migraines $(32,34)$.

Another systemic symptom associated with dysmenorrhea is fatigue. Wheat has been suggested to boost energy (49). Daily supplementation with wheat (45 g in breakfast, $40 \mathrm{~g}$ between meals, and $40 \mathrm{~g}$ in dinner) for two months has been found to decrease the feeling of tiredness by 75\% (50). The vitamin B family, magnesium, and zinc in wheat germ reduce the severity of fatigue (51). Accordingly, the vitamin B family, magnesium, and zinc 
content of wheat germ might be responsible for reduced fatigue levels in the current study.

Mood swings are also among the systemic symptoms accompanying dysmenorrhea. Since vitamin $\mathrm{B}_{6}$ acts as a cofactor during the final stages of serotonin and tryptophan synthesis (52), the sedative effects of wheat germ can be attributed to the presence of this vitamin. On the other hand, magnesium deficiency has been cited as a cause of neural system damage and many conditions including agitation, anxiety, irritability, drowsiness, weakness, insomnia, and headache (48). Hence, the positive effects of wheat germ consumption on fatigue, headaches, mood, and energy level can be caused by its magnesium content. Wheat germ has sedative properties and is effective in the treatment of diseases such as ataxia, nervous system disorders, and acute mental illnesses $(32,34)$. Such findings are comparable to those reported in this study.

The number of consumed sedative tablets was remarkably reduced after intervention in the wheat germ extract group $(\mathrm{P}<0.001)$ while there was no statistically significant change in the placebo group. This is an important finding because NSAIDs have numerous side effects, including nausea, vomiting, dizziness, petechiae, hyperkalemia, peripheral edema, peptic ulcers, and gastric bleeding (31).

A triple-blind clinical trial revealed that using 100 units of vitamin E every six hours for three days decreases the number of consumed sedative tablets (53), which is in accordance with our study and indicates that our results might be due to the effect of vitamin $\mathrm{E}$ in wheat germ.

Our study did not show a significant difference between the two groups with respect to the side effects; in fact, it is not possible to attribute any specific side effect to wheat germ in this study. The findings of this research proved the effectiveness and safety of the daily intake of wheat germ extract for reducing pain severity and systemic manifestations of dysmenorrhea. Padalia et al., in their article, entitled "Multitude potential of Wheatgrass Juice (Green Blood): An overview”, reported no side effects (54), which is in line with our findings. Based on the findings of the present study, further studies are needed to compare wheat germ extract with antiinflammatory medications.

Herbal medicines are among the most common treatments because they are safe and reliable, and have fewer side effects than do chemical medicines. Consumption of wheat germ extract mitigated the severity of pain and systemic manifestations of dysmenorrhea. The therapeutic effects of wheat germ extract might be the consequence of the positive impact of its compounds such as vitamins $\mathrm{B}_{6}$ and $\mathrm{E}$, magnesium, and calcium, and it seems that wheat germ extract can be recommended for treating the dysmenorrhea and its systemic manifestations.

\section{Acknowledgements}

We express our appreciations to the respected officials of the hospitals affiliated with Hamadan University of Medical Sciences, who cooperated with us for executing this research.

\section{Authors' Contributions}

Maryam Atallahi participated in designing the study, data collection, statistical analysis, and writing the manuscript. Sedigheh Amir Ali Akbari helped in designing the study and writing the manuscript. Faraze Mojab participated in manufacturing the drug. Hamid Alavi Majd helped in study design and statistical analysis.

\section{References}

1. Tu CH, Niddam DM, Yeh TC, Lirng JF, Cheng CM, Chou CC, et al Menstrual pain is associated with rapid structural alterations in the brain. Pain. 2013;154(9):1718-24.

2. Younesy S, Amiraliakbari S, Esmaeili S, Alavimajd H, Nouraei S. Effects of fenugreek seed on the severity and systemic symptoms of dysmenorrhea. J Reprod Infertil. 2014;15(1):41-8.

3. Harel Z. Dysmenorrhea in adolescents. Ann $N$ Y Acad Sci. 2008;1135:185-95.

4. Direkvand-Moghadam A, Khosravi A. The impact of a novel herbal Shirazi Thymus Vulgaris on primary dysmenorrhea in comparison to the classical chemical Ibuprofen. J Res Med Sci. 2012;17(7):668-70.

5. Nasehi M, Sehhatie F, Zamanzadeh V, Delazar A, Javadzadeh Y, Chongheralu BM. Comparison of the effectiveness of combination of fennel extract/vitamin E with ibuprofen on the pain intensity in students with primary dysmenorrhea. Iran J Nurs Midwifery Res. 2013;18(5):355-9.

6. Cheng HF, Lin YH. Selection and efficacy of self-management strategies for dysmenorrhea in young Taiwanese women. J Clin Nurs. 2011;20(7-8):1018-25.

7. Iacovides S, Avidon I, Bentley A, Baker FC. Diclofenac potassium restores objective and subjective measures of sleep quality in women with primary dysmenorrhea. Sleep. 2009;32(8):1019-26.

8. French L. Dysmenorrhea in adolescents: diagnosis and treatment. Paediatr Drugs. 2008;10(1):1-7.

9. Turk DC, Melzack R. Handbook of Pain Assessment, Third Edition New York: Guilford Publications; 2011

10. Parker MA, Sneddon AE, Arbon P. The menstrual disorder of teenagers (MDOT) study: determining typical menstrual patterns and menstrual disturbance in a large population-based study of Australian teenagers. BJOG. 2010;117(2):185-92.

11. Harel Z. Dysmenorrhea in adolescents and young adults: etiology and management. J Pediatr Adolesc Gynecol. 2006;19(6):363-71.

12. Mannix LK. Menstrual-related pain conditions: dysmenorrhea and migraine. J Womens Health (Larchmt). 2008;17(5):879-91.

13. Wang L, Cardini F, Zhao W, Regalia AL, Wade C, Forcella E, et al. Vitamin K acupuncture pint injection for severe primary dysmenorrhea: an international pilot study. MedGenMed. 2004;6(4):45

14. Behmanesh F, Zafari M, Zeinalzadeh M, Aghamohammadi A, Akbarpoor S. Comparing the effectiveness of acupressure and fish oil capsules and Ibuprofen on pain severity of primary dysmenorrhea. Indian J Sci Technol. 2012;5(7):3059-64.

15. Zahradnik HP, Hanjalic-Beck A, Groth K. Nonsteroidal anti-inflammatory drugs and hormonal contraceptives for pain relief from dysmenorrhea: a review. Contraception. 2010;81(3):185-96.

16. Daniels SE, Torri S, Desjardins PJ. Valdecoxib for treatment of primary dysmenorrhea. A randomized, double-blind comparison with placebo and naproxen. J Gen Intern Med. 2005;20(1):62-7.

17. Ma H, Hong M, Duan J, Liu P, Fan X, Shang E, et al. Altered cytokine gene expression in peripheral blood monocytes across the menstrual cycle in primary dysmenorrhea: a case-control study. PLoS One. 2013;8(2).

18. Kang HS, Jeong D, Kim DI, Lee MS. The use of acupuncture for managing gynaecologic conditions: An overview of systematic reviews. Maturitas. 2011;68(4):346-54. 
Atallahi M et al.

19. Chapron C, Souza C, Borghese B, Lafay-Pillet MC, Santulli P, Bijaoui $\mathrm{G}$, et al. Oral contraceptives and endometriosis: the past use of oral contraceptives for treating severe primary dysmenorrhea is associated with endometriosis, especially deep infiltrating endometriosis. Hum Reprod. 2011;26(8):2028-35.

20. Dmitrovic R, Kunselman AR, Legro RS. Continuous compared with cyclic oral contraceptives for the treatment of primary dysmenorrhea: a randomized controlled trial. Obstet Gynecol. 2012;119(6):1143-50.

21. Proctor M, Farquhar C. Diagnosis and management of dysmenorrhoea. BMJ. 2006;332(7550):1134-8.

22. Valiani M, Babaei E, Heshmat R, Zare Z. Comparing the effects of reflexology methods and Ibuprofen administration on dysmenorrhea in female students of Isfahan University of Medical Sciences. Iran J Nurs Midwifery Res. 2010;15(Suppl1):371-8.

23. Bettendorf B, Shay S, Tu F. Dysmenorrhea: contemporary perspectives. Obstet Gynecol Surv. 2008;63(9):597-603.

24. Habek D, Cerkez Habek J, Bobic-Vukovic M, Vujic B. Efficacy of Acupuncture for the Treatment of Primary Dysmenorrhea. Gynakol Geburtshilfliche Rundsch. 2003;43(4):250-3.

25. Cochrane S, Smith CA, Possamai-Inesedy A, Bensoussan A. Acupuncture and women's health: an overview of the role of acupuncture and its clinical management in women's reproductive health. Int J Womens Health. 2014;6:313-25.

26. Micozzi MS, Dog TL. Women's Health in Complementary and Integrative Medicine: A Clinical Guide.St.Louis Missouri: Elsevier Health Sciences; 2004.

27. Bani S, Hasanpour S, Mousavi Z, Mostafa Garehbaghi P, Gojazadeh M. The Effect of Rosa Damascena Extract on Primary Dysmenorrhea: A Double-blind Cross-over Clinical Trial. Iran Red Crescent Med J. 2014;16(1):14643.

28. Tseng YF, Chen CH, Yang YH. Rose tea for relief of primary dysmenorrhea in adolescents: a randomized controlled trial in Taiwan. J Midwifery Womens Health. 2005;50(5):e51-7.

29. Namavar Jahromi B, Tartifizadeh A, Khabnadideh S. Comparison of fennel and mefenamic acid for the treatment of primary dysmenorrhea. Int J Gynaecol Obstet. 2003;80(2):153-7.

30. Ostad SN, Soodi M, Shariffzadeh M, Khorshidi N, Marzban H. The effect of fennel essential oil on uterine contraction as a model for dysmenorrhea, pharmacology and toxicology study. J Ethnopharmacol. 2001;76(3):299-304.

31. Mirabi P, Dolatian M, Mojab F, Majd HA. Effects of valerian on the severity and systemic manifestations of dysmenorrhea. Int J Gynaecol Obstet. 2011;115(3):285-8.

32. Desai TR. . Invetigation into the Mechanism of Action and Effects of Triticum Aestivum (Wheat) Grass.. : Saurashtra University; 2005.

33. Singh N, Verma P, Pandey BR. Therapeutic Potential of Organic Triticum aestivum Linn.(Wheat Grass) in Prevention and Treatment of Chronic Diseases: An Overview. IJPSDR. 2012;4(1):10-4.

34. Kumar P, Yadava RK, Gollen B, Kumar S, Verma RK, Yadav S. Nutritional contents and medicinal properties of wheat: A review. Life Sci Med Res. 2011;22:1-10.

35. Avasarala AK, Panchangam S. Dysmenorrhoea in different settings: are the rural and urban adolescent girls perceiving and managing the dysmenorrhoea problem differently? Indian $J$ Community Med.2008;33(4):246-9.
36. Ziaei S, Faghihzadeh S, Sohrabvand F, Lamyian M, Emamgholy T. A randomised placebo-controlled trial to determine the effect of vitamin $\mathrm{E}$ in treatment of primary dysmenorrhoea. BJOG. 2001;108(11):1181-3.

37. French L. Dysmenorrhea. Am Fam Physician. 2005;71(2):285-91.

38. Nahid K, Fariborz M, Ataolah G, Solokian S. The effect of an Iranian herbal drug on primary dysmenorrhea: a clinical controlled trial.J Midwifery Womens Health. 2009;54(5):401-4.

39. Han SH, Hur MH, Buckle J, Choi J, Lee MS. Effect of aromatherapy on symptoms of dysmenorrhea in college students: A randomized placebo-controlled clinical trial. J Altern Complement Med. 2006;12(6):535-41.

40. Nagata C, Oba S, Shimizu H. Associations of menstrual cycle length with intake of soy, fat, and dietary fiber in Japanese women. Nutr Cancer. 2006;54(2):166-70.

41. Nagata C, Hirokawa K, Shimizu N, Shimizu H. Associations of menstrual pain with intakes of soy, fat and dietary fiber in Japanese women. Eur JClin Nutr. 2005;59(1):88-92.

42. Stone A. Migraine Headache Treated with Acupuncture and Herbs. 2009.

43. Ziaei S, Zakeri M, Kazemnejad A. A randomised controlled trial of vitamin $\mathrm{E}$ in the treatment of primary dysmenorrhoea. BJOG. 2005;112(4):466-9.

44. Lasco A, Catalano A, Benvenga S. Improvement of primary dysmenorrhea caused by a single oral dose of vitamin D: results of a randomized, double-blind, placebo-controlled study. Arch Intern Med. 2012;172(4):366-7.

45. Zafari M, Tofighi M, Aghamohammady A, Behmanesh F, Rakhshaee Z. Comparison of the effect of acupressure, fish oil capsules and ibuprofen on treatment of primary dysmenorrhea. Afr JPharmacy Pharmacol. 2011;5(8):1115-9.

46. Doty E, Attaran M. Managing primary dysmenorrhea. J Pediatr Adolesc Gynecol. 2006;19(5):341-4.

47. Jurgens T, Whelan AM. Advising patients on the use of natural health products to treat premenstrual syndrome. Can Pharm J (Ott). 2009;142(5):228-33.

48. Panay N. Management of premenstrual syndrome. J Fam Plann Reprod Health Care. 2009;35(3):187-94.

49. Eby GA, Eby KL. Rapid recovery from major depression using magnesium treatment. Med Hypotheses. 2006;67(2):362-70.

50. Coppen A, Bolander-Gouaille C. Treatment of depression: time to consider folic acid and vitamin B12.J Psychopharmacol. 2005;19(1):59-65.

51. Kochhar A, Gulati K, Sachdeva R. Impact of Instant Wheat Meal Supplementation and Nutrition Counselling On Anthropometry and Blood Pressure of Non Insulin Dependent Diabetics. Age. 2009;40(50):19.

52. Ghanbari Z, Haghollahi F, Shariat M, Foroshani AR, Ashrafi M. Effects of calcium supplement therapy in women with premenstrual syndrome. Taiwan J Obstet Gynecol. 2009;48(2):124-9.

53. Moslemi L, Bekhradi R, Galini Moghaddam T, Gholamitabar Tabari M. Comparative effect of fennel extract on the intensity of primary dysmenorrhea. African J Pharm Pharmacol. 2012;6:1770-3.

54. Padalia S, Drabu S, Raheja I, Gupta A, Dhamija M. Multitude potential of Wheatgrass Juice (Green Blood): An overview. Chronicles of Young Sci.2010;1(2):23-8. 